\title{
DISPONIBILIDADE E RECUPERAÇÃO DE NUTRIENTES DE RESÍDUOS CULTURAIS EM SOLO COM DIFERENTES TEXTURAS
}

\author{
Henrique José Guimarães Moreira Maluf ${ }^{(1)^{*}}$, Emanuelle Mercês Barros Soares ${ }^{(2)}$, Ivo Ribeiro \\ da Silva ${ }^{(2)}$, Júlio César Lima Neves ${ }^{(2)}$ e Mailson Félix de Oliveira Silva ${ }^{(3)}$ \\ (1) Universidade Federal de Lavras, Departamento de Ciência do Solo, Programa de Pós-Graduação em Ciência do Solo, Lavras, \\ Minas Gerais, Brasil. \\ (2) Universidade Federal de Viçosa, Departamento de Solos, Viçosa, Minas Gerais, Brasil. \\ (3) Universidade Federal de Viçosa, Graduação em Agronomia, Viçosa, Minas Gerais, Brasil. \\ * Autor correspondente. \\ E-mail: maluf.henrique@yahoo.com.br
}

\section{RESUMO}

Os resíduos de culturas agrícolas aportados sobre a superfície do solo, além da proteção física, podem liberar quantidades significativas de nutrientes ao solo pela decomposição deles; porém, a disponibilidade desses nutrientes às plantas é um fator pouco estudado. Avaliaram-se os teores totais de $\mathrm{C}$ orgânico e $\mathrm{N}$, o pH e a disponibilidade e taxa de recuperação dos macronutrientes provenientes da ciclagem biogeoquímica de diferentes resíduos culturais ao longo do tempo, em solos com texturas construídas. Os tratamentos consistiram em fatorial $6 \times 4 \times 5$, composto por seis tratamentos no primeiro fator, sendo quatro resíduos culturais: milho, braquiária, feijão, estilosantes, e dois controles, ambos sem resíduo e um com adição de fontes inorgânicas dos nutrientes; quatro diferentes texturas formadas a partir de um mesmo solo e cinco tempos de avaliação, após o início da incubação: $0,25,75,125$ e 175 dias; utilizou-se delineamento inteiramente casualizado, com quatro repetições. $O$ tipo de resíduo, a textura do solo e o tempo de incubação influenciaram os teores totais de $\mathrm{C}$ orgânico e $\mathrm{N}$, o pH, a disponibilidade e a taxa de recuperação de $\mathrm{P}, \mathrm{K}, \mathrm{Ca}$, Mg e $\mathrm{S}$. Os teores totais de $\mathrm{C}$ orgânico e $\mathrm{N}$ nos solos diminuíram ao longo da incubação. Os resíduos de braquiária e estilosantes acidificaram o solo. $\mathrm{O}$ resíduo de braquiária apresentou-se como potencial fonte de K; e o de feijão, de S. O resíduo de milho apresentou as maiores taxas de recuperação de $\mathrm{P}$ em solos de textura média e argilosa.

Palavras-chave: ciclagem de nutrientes, fertilidade do solo, carbono orgânico, nitrogênio total, pH do solo. 


\title{
ABSTRACT: NUTRIENT AVAILABILITY AND RECOVERY FROM CROP RESIDUES IN SOIL WITH DIFFERENT TEXTURES
}

\begin{abstract}
Crop residues on the soil surface not only provide physical protection but may release significant amounts of nutrients to the soil through decomposition. However, the availability of these nutrients to plants has not been sufficiently studied. The aim of this study was to evaluate the total contents of organic $C$ and $N, p H$, and the availability and recovery rate of $P, K, C a, M g$, and $S$ from the biogeochemical cycling of different crop residues over time in built soils with different textures. The experimental design consisted of a $6 \times 4 \times 5$ factorial arrangement - six treatments, composed of four crop residues (corn, Brachiaria, common bean, and Stylosanthes) and two controls, both without residues, and only one with the addition of inorganic nutrient sources; four different textures formed from the same soil; and evaluation after five incubation times $(0,25,75,125$, and 175 days). A completely randomized design was used, with four replications. The type of crop residue, soil texture, and incubation time influenced the total concentration of organic $C$ and $N, p H$, and macronutrient bioavailability and recovery rate. The total contents of organic $C$ and $N$ in soils decreased over the incubation period. The Brachiaria and Stylosanthes residues acidified the soil. Brachiaria residue proved to be a potential source of $K$, and common bean, of $S$. The $P$ from corn residue had the highest recovery rate in soils of medium and clayey texture.
\end{abstract}

Keywords: nutrient cycling, soil fertility, organic carbon, total nitrogen, $p H$ of soil.

\section{INTRODUÇÃO}

Entre 2011 e 2013, a demanda brasileira por fertilizantes aumentou, em média, $4,4 \%$ ao ano (ANDA, 2014), sendo o fertilizante potássico o de maior importação, em torno de $95 \%$ (Tavares e Haberli Júnior, 2011), o que implica forte dependência da produção agrícola brasileira a outros países. Para minimizar essa dependência, importantes pesquisas vêm sendo desenvolvidas para viabilizar novas fontes minerais de nutrientes (Duarte et al., 2012); no entanto, alternativas de manejo podem ser vantajosas para reduzir custos de produção e substituir, parcialmente, os fertilizantes (Teixeira et al., 2012), como no sistema plantio direto.

A manutenção e decomposição de resíduos das culturas agrícolas na superfície do solo contribuem para que parte dos nutrientes absorvidos pelas plantas retorne ao solo, podendo ser aproveitados por culturas subsequentes. Embora as pesquisas com ciclagem de nutrientes em agroecossistemas estejam em pleno progresso, envolvendo diversos tipos de resíduos vegetais em diferentes condições edafoclimáticas, pouco se sabe sobre o fluxo e a dinâmica no solo, sendo escassos os estudos com mineralização de nutrientes provenientes de resíduos culturais que dariam continuidade aos trabalhos visando verificar a disponibilidade desses nutrientes para as plantas.

Essa disponibilidade é influenciada por fatores, dentre os quais se destaca a textura do solo. $\mathrm{Na}$ medida em que aumenta o teor de argila do solo, são elevadas a capacidade de troca de cátions e o fator capacidade ou poder-tampão do solo para cátions (Wiethölter, 2007) e ânions, expressos pela redução dos valores de $\mathrm{P}$ remanescente
(Bonfim et al., 2004). No entanto, esse efeito pode ser variável, a depender do tipo de argila, o que pode influenciar nas respostas quando a pergunta está relacionada somente à quantidade de argila para modelagem e não à qualidade. A mineralogia influencia a disponibilidade de nutrientes no solo e, em alguns casos, sobrepõe o efeito da textura, como observado por Moreira et al. (2006), onde as maiores adsorções de $\mathrm{P}$ não ocorreram em solos com maior teor de argila e sim naqueles que apresentaram maior teor de Fe total e óxidos de Fe amorfo, o que interfere na disponibilidade desse nutriente para as plantas. Há trabalhos que também apresentaram a preponderância da mineralogia da fração argila na adsorção e disponibilidade de $\mathrm{P}$ no solo, como os de Farias et al. (2009), Wisawapipat et al. (2009) e Pinto et al. (2013). Da mesma forma que a disponibilidade de ânions é dependente das cargas superficiais das argilas e, por sua vez da mineralogia, essa também influencia a CTC e a disponibilidade de nutrientes catiônicos no solo.

A utilização de solo muito argiloso com adição de areia, em diferentes proporções, pode expressar resultados intrínsecos à textura do solo, apresentando o real efeito da composição granulométrica sobre a disponibilidade de nutrientes no solo, sem interferência da variação mineralógica da argila. Entretanto, a segregação dificultaria a formação de misturas homogêneas; para isso, ciclos de umedecimento e secagem como fator agregante podem promover rearranjo estrutural, favorecendo maior interação entre o solo e as partículas de areia adicionadas, contribuindo com a uniformidade das misturas. A micromorfologia de agregados integrais e moídos de cinco solos com textura e mineralogia distintas foi estudada por Viana et al. (2004), que observaram rearranjo da estrutura com 10 ciclos de 
umedecimento e secagem, em condição controlada, contribuindo para agregação desses solos.

O estudo do fluxo e o da dinâmica de nutrientes, em condição controlada, visam obter informações com menor possibilidade de erro durante o processo experimental, a fim de investigar o potencial de cada resíduo cultural, culturas comerciais e de cobertura, na disponibilidade de nutrientes provindos da ciclagem biogeoquímica, o que contribui e incentiva o desenvolvimento e aprimoramento de sistemas de recomendação de corretivos e fertilizantes. O balanço de nutrientes é um método eficiente para estimar a necessidade de adubação para as culturas e vem sendo incorporado a recentes sistemas de recomendação de corretivos e fertilizantes, como o FERTCALC. Esse sistema, desenvolvido para diversas culturas, estabelece o balanço entre a demanda de nutrientes pela cultura e o suprimento pelo solo, pelos resíduos culturais e outras fontes naturais (Cantarutti et al., 2007). Porém, o suprimento de nutrientes via resíduos culturais é fornecido, unicamente, por informações da mineralização/liberação, sem a existência de relações com a disponibilidade desses nutrientes em solos com texturas distintas, podendo superestimar o suprimento de nutrientes às plantas.

Objetivou-se com este trabalho avaliar os teores totais de $\mathrm{C}$ orgânico e $\mathrm{N}$, o $\mathrm{pH}$ e a disponibilidade e recuperação, pelos extratores, do $\mathrm{P}, \mathrm{K}, \mathrm{Ca}, \mathrm{Mg}$ e $\mathrm{S}$ provenientes da ciclagem biogeoquímica de resíduos culturais, em solo com diferentes texturas ao longo de 175 dias de incubação.

\section{MATERIAL E MÉTODOS}

O experimento foi desenvolvido em sala de incubação com temperatura controlada a $25 \pm 1{ }^{\circ} \mathrm{C}$. Os tratamentos foram constituídos por fatorial $6 \times 4 \times 5$, onde o primeiro fator foi composto por quatro tipos de resíduos culturais e dois controles: milho (Zea mays L.), braquiária (Urochloa ruziziensis Germain et Evrard), feijão-comum (Phaseolus vulgaris L.), estilosantes cv. Mineirão (Stylosanthes guianensis Aublet), e os dois controles, sem resíduo; porém, um com adição de fontes inorgânicas dos nutrientes, representadas pelas quantidades médias de nutrientes presentes nos resíduos, e o outro, sem aplicação de resíduos culturais e nutrientes em formas minerais, denominado controle absoluto. $\mathrm{O}$ segundo fator compôs-se de quatro solos com diferentes texturas construídas; e o terceiro, de cinco tempos de avaliação: $0,25,75,125$ e 175 dias, após o início da incubação (DAI). Utilizou-se delineamento inteiramente casualizado, com quatro repetições.

As diferentes texturas dos solos foram construídas por meio de amostras de um Latossolo
Vermelho-Amarelo Distrófico de textura muito argilosa com predominância de caulinita na fração argila, coletado em área de pastagem na camada de 0,00-0,20 m, misturando com areia peneirada em malha de $1 \mathrm{~mm}$, em diferentes proporções, para que os solos se enquadrassem nas classes texturais: argilosa, média e arenosa, conforme a classificação da Embrapa (2006). Essas misturas, solo muito argiloso e areia, foram desenvolvidas para minimizar ou controlar outros efeitos além da textura, como a mineralogia dos solos, especialmente da fração argila, expressando os verdadeiros efeitos da textura (composição granulométrica) do solo. Para evitar a segregação da areia adicionada e o solo muito argiloso e promover maior interação entre os constituintes minerais, cada mistura foi submetida a 12 ciclos de umedecimento e secagem. As características físicas e químicas dos solos oriundos dessas misturas (diferentes texturas) são apresentadas no quadro 1.

A unidade experimental foi composta por recipiente de polietileno com tampa, de $0,11 \mathrm{~m}$ de diâmetro e capacidade de $500 \mathrm{~mL}$, contendo $130 \mathrm{~g}$ de solos seco com umidade corrigida para $80 \%$ da capacidade de campo. Os resíduos culturais depois de secos à sombra foram fragmentados manualmente em partículas de 0,01 a 0,02 m e distribuídos sobre tela de polietileno, com abertura de $2 \mathrm{~mm}$, previamente posicionada sobre o solo, onde foram umedecidos inicialmente com $10 \mathrm{~mL}$ de água deionizada. Os recipientes foram abertos a cada dois dias, por $15 \mathrm{~min}$, para que ocorressem as trocas gasosas. Também, os resíduos foram reumedecidos com $10 \mathrm{~mL}$ de água deionizada, sempre que necessário, para evitar a perda excessiva de umidade tanto do resíduo quanto do solo.

O solo coletado de cada recipiente aos $0,25,75$, 125 e 175 DAI foram secos em estufa de circulação de ar forçada, a $60{ }^{\circ} \mathrm{C}$ por $48 \mathrm{~h}$, e peneirados em malha de $2 \mathrm{~mm}$, para avaliar os atributos químicos do solo, nos mesmos métodos analisados para a caracterização (Quadro 1): $\mathrm{pH}$ em água, 1:2,5 (v/v), $\mathrm{Ca}^{2+}$ e de $\mathrm{Mg}^{2+}$ com extração em $\mathrm{KCl} 1 \mathrm{~mol} \mathrm{~L}^{-1} \mathrm{e}$ determinação em espectrofotometria de absorção atômica; S, por fosfato monocálcico em ácido acético $2 \mathrm{~mol} \mathrm{~L}^{-1}$ e dosagem por turbidimetria, com determinação por espectrofotometria UV-visível a $420 \mathrm{~nm}$ (Alvarez V et al., 2001); e P e K, por Mehlich-1, com determinação do $\mathrm{P}$ por colorimetria (Braga e Defelipo, 1974) e do K por fotometria de emissão de chama. Também, as amostras de solo coletadas em cada avaliação foram maceradas em almofariz de ágata e peneirada em malha de $0,25 \mathrm{~mm}$ para as determinações dos teores totais de C orgânico (Yeomans e Bremner, 1988) e de N, pelo método Kjeldahl.

A taxa de recuperação foi calculada para os macronutrientes, a fim de indicar a quantidade do nutriente disponível para a planta, recuperado 
Quadro 1. Características físicas e químicas dos solos com diferentes texturas antes do período de incubação

\begin{tabular}{|c|c|c|c|c|}
\hline Attribute & Muito argilosa & Argilosa & Média & Arenosa \\
\hline Argila $\left(\mathrm{g} \mathrm{kg}^{-1}\right)^{(1)}$ & 620,4 & 460,3 & 266,7 & 143,9 \\
\hline $\mathrm{pH}\left(\mathrm{H}_{2} \mathrm{O}\right)$ & 4,78 & 4,87 & 5,09 & 5,62 \\
\hline Carbono orgânico $\left(\mathrm{g} \mathrm{kg}^{-1}\right)^{(2)}$ & 11,08 & 8,47 & 6,14 & 3,94 \\
\hline Nitrogênio total $\left(\mathrm{g} \mathrm{kg}^{-1}\right)^{(3)}$ & 0,97 & 0,75 & 0,47 & 0,39 \\
\hline $\left.\mathrm{P}(\mathrm{mg} \mathrm{dm})^{-3}\right)^{(4)}$ & 1,54 & 1,63 & 1,73 & 2,01 \\
\hline $\left.\mathrm{K}(\mathrm{mg} \mathrm{dm})^{-3}\right)^{(4)}$ & 25,78 & 20,76 & 13,73 & 8,70 \\
\hline P-rem $\left(\mathrm{mg} \mathrm{L}^{-1}\right)^{(5)}$ & 8,58 & 11,33 & 18,08 & 32,27 \\
\hline $\mathrm{Ca}^{2+}\left(\mathrm{cmol}_{\mathrm{c}} \mathrm{dm}^{-3}\right)^{(6)}$ & 0,31 & 0,26 & 0,23 & 0,13 \\
\hline $\mathrm{Mg}^{2+}\left(\mathrm{cmol}_{\mathrm{c}} \mathrm{dm}^{-3}\right)^{(6)}$ & 0,04 & 0,04 & 0,03 & 0,03 \\
\hline $\mathrm{Al}^{3+}\left(\mathrm{cmol}_{\mathrm{c}} \mathrm{dm}^{-3}\right)^{(6)}$ & 0,67 & 0,44 & 0,21 & 0,00 \\
\hline $\mathrm{H}+\mathrm{Al}\left(\mathrm{cmol}_{\mathrm{c}} \mathrm{dm}^{-3}\right)^{(7)}$ & 8,67 & 7,54 & 5,94 & 4,24 \\
\hline CTC efetiva $\left(\mathrm{cmol}_{\mathrm{c}} \mathrm{dm}^{-3}\right)$ & 1,09 & 0,79 & 0,51 & 0,18 \\
\hline CTC a pH $7,0\left(\mathrm{cmol}_{\mathrm{c}} \mathrm{dm}^{-3}\right)$ & 9,09 & 7,89 & 6,23 & 4,42 \\
\hline $\mathrm{V}(\%)$ & 4,58 & 4,47 & 4,74 & 4,12 \\
\hline $\left.\mathrm{S}(\mathrm{mg} \mathrm{dm})^{-3}\right)^{(8)}$ & 10,39 & 11,84 & 17,09 & 18,47 \\
\hline $\mathrm{Cu}\left(\mathrm{mg} \mathrm{dm}^{-3}\right)^{(5)}$ & 1,67 & 1,32 & 1,03 & 0,58 \\
\hline $\mathrm{Zn}\left(\mathrm{mg} \mathrm{dm}^{-3}\right)^{(5)}$ & 0,46 & 0,42 & 0,41 & 0,38 \\
\hline
\end{tabular}

(1) Método da pipeta (Embrapa, 2011); ${ }^{(2)}$ Yeomans e Bremner (1988); ${ }^{(3)}$ Método Kjeldahl; (4) Mehlich-1; ${ }^{(5)}$ P-rem: P remanescente (Alvarez V et al., 2000). ${ }^{(6)} \mathrm{KCl} 1 \mathrm{~mol} \mathrm{L-1;}{ }^{(7)}$ Solução de acetato de cálcio 0,5 mol L ${ }^{-1}$, pH 7,0; ${ }^{(8)}$ Fosfato monocálcico em ácido acético $2 \mathrm{~mol} \mathrm{~L}^{-1}$. CTC: capacidade de troca catiônica efetiva e $\mathrm{pH}$ 7,0, respectivamente; V: Saturação por bases.

pelo extrator, por unidade do nutriente liberado do resíduo ou aplicado na forma inorgânica.

TR $(\%)=($ Tratamento - Controle $) /$ Resíduo $) \times 100$

em que Tratamento é a quantidade do nutriente disponível no solo com resíduo ou no solo onde foi aplicado nutrientes na forma inorgânica; Controle, a quantidade do nutriente disponível no solo do controle absoluto; e Resíduo, a quantidade do nutriente liberada do resíduo cultural ou aplicado na forma inorgânica.

Os dados foram submetidos à análise da variância e regressão múltipla para os teores totais de $\mathrm{C}$ orgânico e $\mathrm{N}$, valores de $\mathrm{pH}$, teores dos macronutrientes disponíveis e taxas de recuperação no solo em razão do teor de argila e do tempo de incubação, utilizando o RSREG do programa SAS versão 9 (SAS, 2002). A escolha do modelo de regressão foi feita com base no menor valor da soma dos quadrados do erro, na significância dos parâmetros da equação $(\mathrm{p}<0,05)$ e no maior valor do coeficiente de determinação $\left(\mathrm{R}^{2}\right)$ ajustado.

\section{RESULTADOS E DISCUSSÃO}

Todas as variáveis avaliadas foram influenciadas pela interação entre tipos de resíduos, textura do solo e tempo de incubação $(p<0,05)$. Os teores de
C orgânico total diminuíram ao longo do tempo de incubação (Figura 1), indicando que a aplicação única de resíduo cultural ou de fontes inorgânicas dos nutrientes e as condições do ambiente de incubação estimularam a atividade microbiana, o que favoreceu a mineralização do $\mathrm{C}$ orgânico existente nos solos estudados. A aplicação de fonte externa de $\mathrm{C}$ favoreceu a mineralização do $\mathrm{C}$ nativo dos solos, principalmente quando esses possuíam maiores teores de nutrientes (Zhang et al., 2013).

Os teores de $\mathrm{N}$ total tenderam a diminuir nos solos de todos os tratamentos ao longo da incubação; essas reduções foram menos pronunciadas nos solos com resíduos de braquiária e de estilosantes (Figura 1), o que está relacionado à maior mineralização do $\mathrm{N}$ presente nesses resíduos. Porém, o efeito da mineralização do $\mathrm{N}$ nos primeiros dias após o início da incubação (DAI) não foi observada no solo; inicialmente, parte do $\mathrm{N}$ pode ter sido perdido por volatilização, na forma de $\mathrm{NH}_{3}$, antes de formar $\mathrm{NH}_{4}^{+}$em condição ácida. A alcalinidade no extrato de resíduos culturais em decomposição, após 15 dias de incubação, foi observada por Franchini et al. (2001). Esse efeito favoreceria a formação de $\mathrm{NH}_{3}$ e as perdas iniciais de N por volatilização. Entretanto, ao final da incubação, os teores de $\mathrm{N}$ total nos tratamentos que receberam a aplicação de resíduos tenderam a aumentar.

Os valores de $\mathrm{pH}$ diminuíram ao longo do tempo de avaliação nos solos que receberam resíduos de braquiária e de estilosantes (Figura 2); essa acidificação 
$\operatorname{COT}=0,21+0,01 * * a-0,0002 \mathrm{t}-0,000001 \mathrm{a}^{2}$ $+0,00003^{* *} \mathrm{ta}-0,00001^{* *} \mathrm{t}^{2}\left(\mathrm{R}^{2}=0,96\right)$

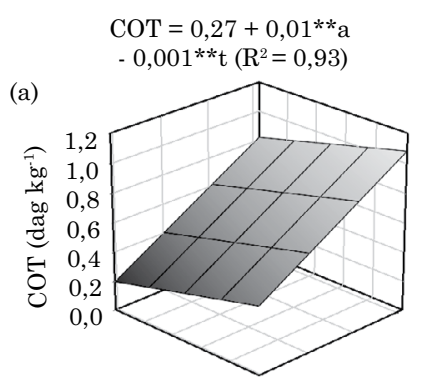

(b)

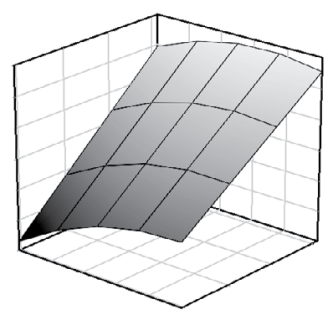

$\operatorname{COT}=0,24+0,01 * * a-0,001 * * t+0,0001^{*} \mathrm{a}^{2}$ $-0,00001 * \mathrm{ta}+0,000005 \mathrm{t}^{2}\left(\mathrm{R}^{2}=0,94\right)$



$\mathrm{NT}=0,03+0,003^{* *} \mathrm{a}-0,00008^{*} \mathrm{t}$ - $0,00002^{* *} \mathrm{a}^{2}\left(\mathrm{R}^{2}=0,94\right)$


(e)

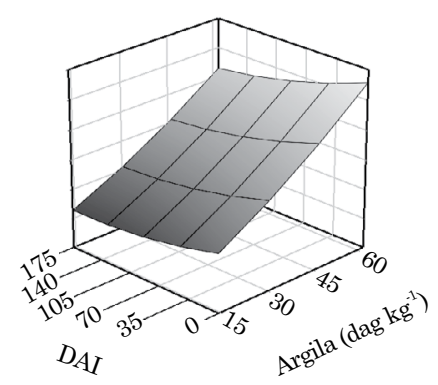
$\mathrm{NT}=0,01+0,001^{* *} \mathrm{a}-0,0004^{* *} \mathrm{t}$ $+0,000001^{* *} \mathrm{t}^{2}\left(\mathrm{R}^{2}=0,88\right)$

(b)

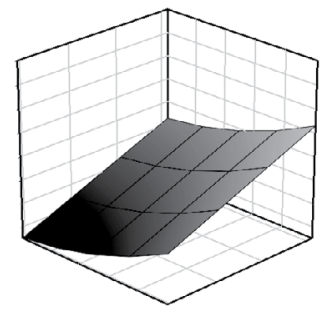

$\mathrm{NT}=0,02+0,001^{* *} \mathrm{a}-0,0004^{* *} \mathrm{t}$

(e)

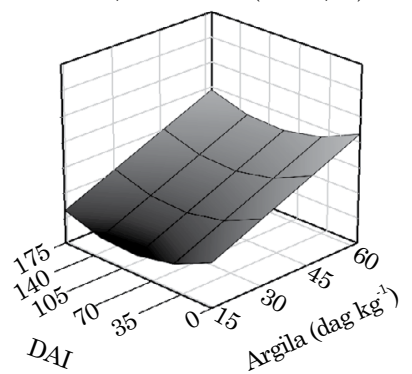

$\mathrm{COT}=0,37+0,01^{* *} \mathrm{a}-0,002 * * \mathrm{t}\left(\mathrm{R}^{2}=0,90\right)$

(c)

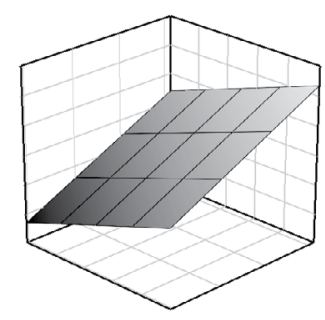

$\mathrm{COT}=0,24+0,01^{* *} \mathrm{a}$ $-0,0003^{* *} \mathrm{t}\left(\mathrm{R}^{2}=0,91\right)$

(f)



$\begin{aligned} \mathrm{NT} & =0,01+0,001^{* *} \mathrm{a}-0,0004^{* *} \mathrm{t} \\ & +0,000002^{* *} \mathrm{t}^{2}\left(\mathrm{R}^{2}=0,90\right)\end{aligned}$

(c)

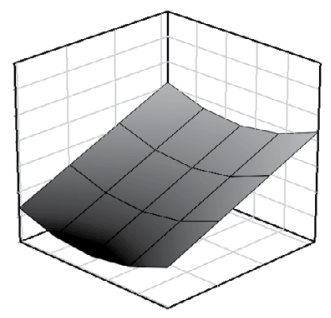

$$
\begin{aligned}
\mathrm{NT} & =0,02+0,001^{* *} \mathrm{a}-0,0002^{* * *} \mathrm{t} \\
& +0,000001^{* *} \mathrm{t}^{2}\left(\mathrm{R}^{2}=0,90\right)
\end{aligned}
$$

(f)

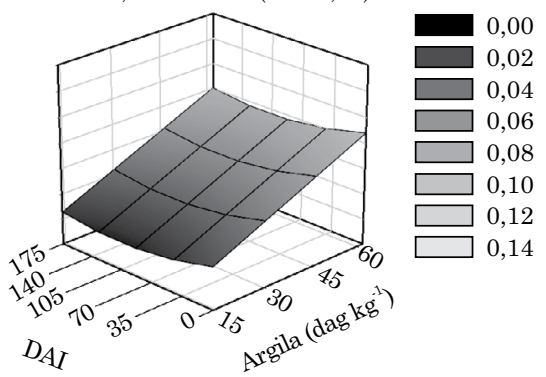

Figura 1. Carbono orgânico total (COT) e nitrogênio total (NT) nos solos com fontes inorgânicas dos nutrientes (a), sem adição de nutrientes e resíduo (b); e com resíduo de milho (c), braquiária (d), feijão (e) e estilosantes (f). * e **: significativos a 5 e $1 \%$, respectivamente, referentes às variáveis: a - teor de argila, $t$ - tempo e ta - interação entre esses. DAI: dias após o início da incubação.

pode estar relacionada com as transformações do $\mathrm{N}$, particularmente ao final da incubação, onde houve maior tendência de aumento dos teores desse nutriente. A influência de compostos orgânicos nas alterações do $\mathrm{pH}$ em solos incubados foi estudada por Yan et al. (1996), os quais observaram queda dos valores de $\mathrm{pH}$, resultante do processo de nitrificação.
Em estudo realizado em campo, Santos et al. (2012) verificaram maior acidificação em áreas com resíduos de braquiária e de estilosantes.

De forma inversa, os resíduos de milho e, principalmente, de feijão, que possuíam os menores teores de $\mathrm{N}$, aumentaram o $\mathrm{pH}$ no final dos $175 \mathrm{DAI}$ em solos com menor teor de argila (Figura 2). A 


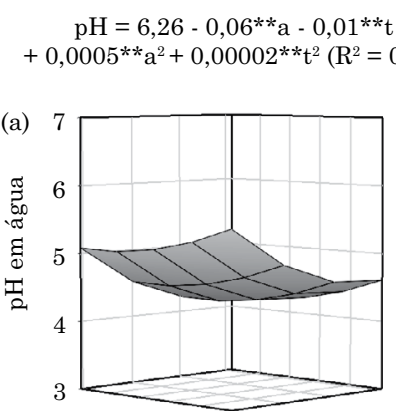

$\mathrm{pH}=6,44-0,02^{* *} \mathrm{a}$ $-0,008 * * t\left(R^{2}=0,52\right)$

(d)

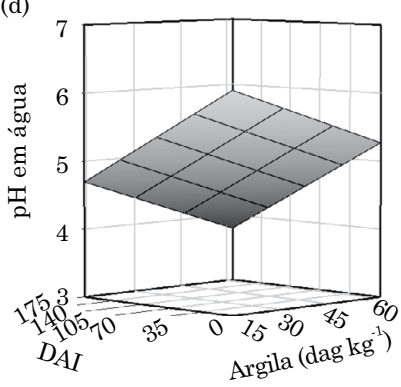

$\mathrm{pH}=6,51-0,07^{* *} \mathrm{a}-0,005^{* *} \mathrm{t}+0,0007^{* *} \mathrm{a}^{2}$ $-0,00005^{* *} \mathrm{ta}+0,00003^{* *} \mathrm{t}^{2}\left(\mathrm{R}^{2}=0,84\right)$

(b)

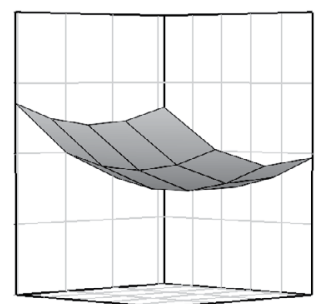

$\mathrm{pH}=6,48-0,07 * * \mathrm{a}+0,007 * * \mathrm{t}$ $+0,0007^{* *} \mathrm{a}^{2}-0,0001^{* *}$ ta

(e) - $0,0000009 \mathrm{t}^{2}\left(\mathrm{R}^{2}=0,94\right)$

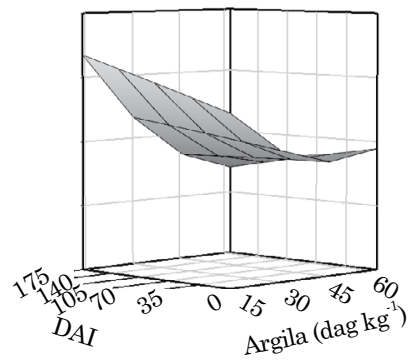

$\mathrm{H}=6,57-0,07 * * \mathrm{a}-0,001^{* *} \mathrm{t}+0,0007 * * \mathrm{a}^{2}$ $-0,0001^{* *} \mathrm{ta}+0,00002^{* *} \mathrm{t}^{2}\left(\mathrm{R}^{2}=0,95\right)$

(c)



$\mathrm{pH}=6,49-0,05^{* *} \mathrm{a}-0,01^{* *} \mathrm{t}$ $+0,0005^{*} \mathrm{a}^{2}\left(\mathrm{R}^{2}=0,74\right)$

(f)

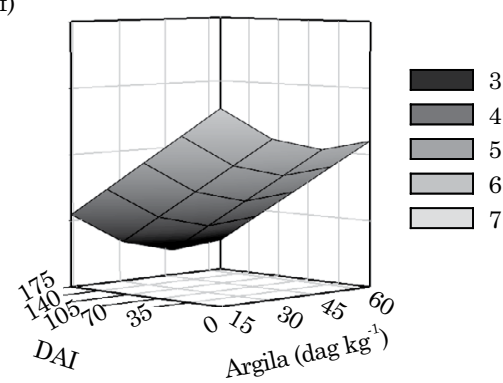

Figura 2. pH em água nos solos com fontes inorgânicas dos nutrientes (a), sem adição de nutrientes e resíduo (b); e com resíduo de: milho (c), braquiária (d), feijão (e) e estilosantes (f). * e **: significativos a 5 e $1 \%$, respectivamente, referentes às variáveis: a - teor de argila, $t$ - tempo e ta - interação entre estes. DAI: dias após o início da incubação.

oxidação biológica, além de consumir prótons, libera elétrons, além da capacidade dos ácidos orgânicos de complexarem $\mathrm{H}^{+}$e $\mathrm{Al}^{3+}$, aumentando os valores de $\mathrm{pH}$ do solo (Yan et al., 1996; Pavinato e Rosolem, 2008). Dessa forma, o teor de $\mathrm{N}$ de resíduos culturais e a taxa de mineralização desse nutriente podem regular os valores de $\mathrm{pH}$ do solo.

A maior contribuição dos resíduos, em relação ao aumento da disponibilidade de nutrientes no solo, foi observada para o $\mathrm{K}$, fornecido pelo resíduo de braquiária, na seguinte sequência: braquiária $>$ feijão $>$ milho $>$ estilosantes (Figura 3). $\mathrm{O}$ resíduo de braquiária, especialmente em solo arenoso, contribuiu para o aumento de quase 100 vezes o teor inicial de $\mathrm{K}$ disponível, demonstrando o potencial desse resíduo como fonte de $\mathrm{K}$ para culturas subsequentes. A contribuição dos resíduos culturais em relação ao teor de $\mathrm{K}$ disponível nos solos também pode ser observada pela classificação dos teores iniciais e finais ao longo da avaliação, em que inicialmente foram considerados baixos para os solos muito argiloso e argiloso e muito baixo para os médio e arenoso; no final, aos 175 DAI, os teores nos solos foram classificados como muito bons, como proposto por Alvarez V. et al. (1999).

$\mathrm{O}$ teor de $\mathrm{Mg}^{2+}$ nos solos aumentou gradativamente ao longo da incubação, apresentando os maiores teores em solo arenoso e, principalmente, quando proveniente dos resíduos de braquiária e de feijão (Figura 3), que também apresentaram os maiores teores desse nutriente. A diminuição dos teores de $\mathrm{Ca}^{2+}$ foi observada nos solos de todos os tratamentos. Em um estudo da contribuição de resíduos de nabo-forrageiro, tremoço, aveia-preta, soja e trigo sobre a disponibilidade de $\mathrm{Ca}, \mathrm{Mg}$ e $\mathrm{K}$, incubados em solo arenoso, foi observada maior contribuição para o $\mathrm{K}$ disponível, seguido do $\mathrm{Mg}^{2+}$ e reduções nos teores de $\mathrm{Ca}^{2+}$ no solo. Os autores atribuíram essa redução à complexação por ânions orgânicos, com maior afinidade por $\mathrm{Ca}$ (Franchini et al., 2001). Entretanto, o Ca pode ter sido imobilizado pela biomassa microbiana do solo, seguindo a relação estequiométrica entre o C e os nutrientes do composto orgânico e as exigências nutricionais dos microrganismos decompositores do solo (Sinsabaugh et al., 2008).

Os teores de $\mathrm{P}$ disponível, aos 175 DAI, nos solos que receberam resíduos culturais foram menores do que aqueles observados com a adição de fonte mineral (Figura 4). Tal efeito indica baixa transferência de $\mathrm{P}$ presente nos resíduos para o solo. O maior aumento do teor de $\mathrm{P}$ disponível foi observado nos solos com resíduo de estilosantes, com teores de, aproximadamente, $3 \mathrm{mg} \mathrm{dm}^{-3}$ para o solo arenoso e de $2 \mathrm{mg} \mathrm{dm}^{-3}$ para o muito argiloso, teores esses ainda considerados muito baixo para solos agrícolas. As diminuições do $\mathrm{P}$ disponível no solo, ao longo da incubação, principalmente com adição de 


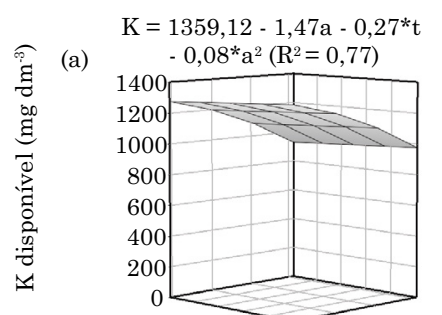

(b)

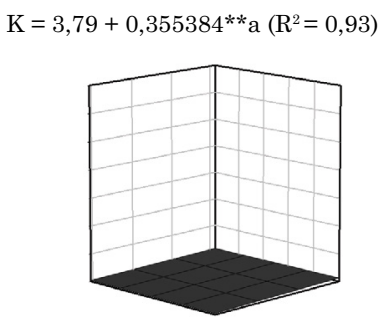

$\mathrm{K}=9,35+0,75 \mathrm{a}+5,83^{* *} \mathrm{t}-0,01 \mathrm{a}$

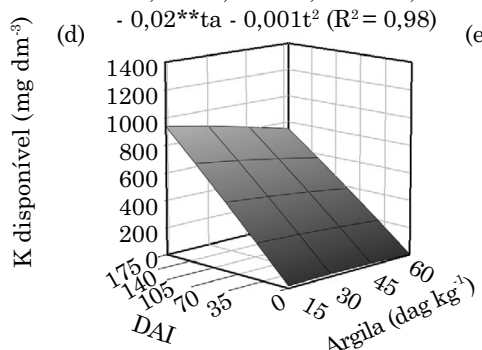

$\mathrm{K}=-22,81+1,27 \mathrm{a}+4,90 * * \mathrm{t}-0,01 \mathrm{a}^{2}$
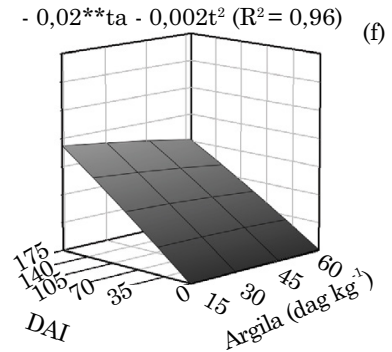

$\mathrm{Mg}=1,96-0,01^{*} \mathrm{a}-0,004^{* *} \mathrm{t}-0,00008 \mathrm{a}^{2} \mathrm{Mg}=0,03+0,000188^{* *} \mathrm{a}-0,0003^{* * *} \mathrm{t}$ $+0,00005^{* *} \mathrm{ta}+0,000007 \mathrm{t}^{2}\left(\mathrm{R}^{2}=0,81\right)$

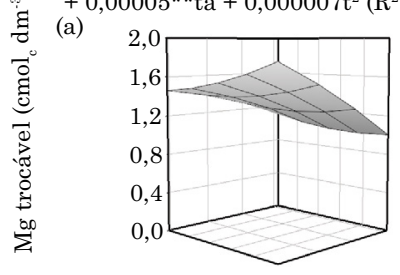

$\mathrm{Mg}=0,003+0,0006 \mathrm{a}+0,003^{* * \mathrm{t}}$ $-0,000002 \mathrm{a}^{2}-0,00002^{* *} \mathrm{ta}$

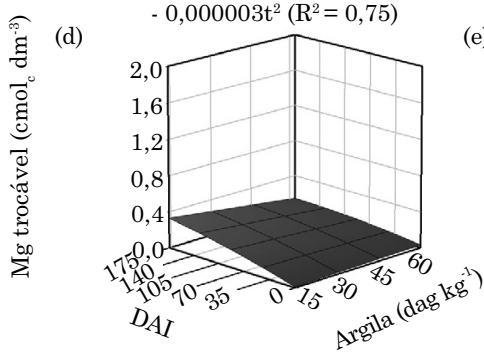

(b)

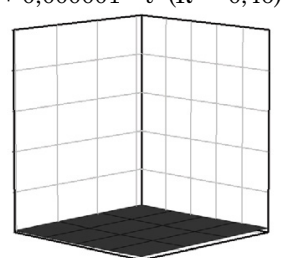

(c)

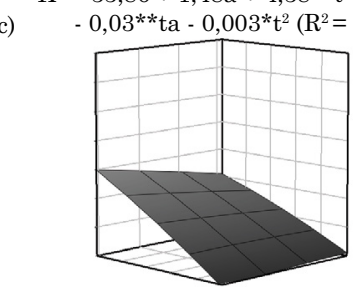

$\mathrm{K}=-25,18+1,31 \mathrm{a}+3,05^{* * *} \mathrm{t}-0,01 \mathrm{a}^{2}$

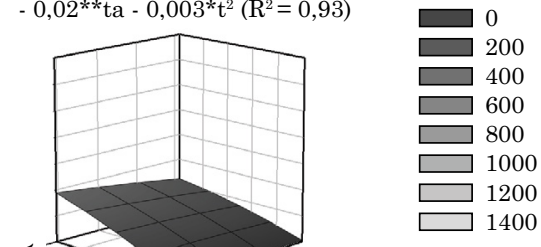

(e)

$\mathrm{Mg}=0,03-0,0006 \mathrm{a}+0,003^{* *} \mathrm{t}$ $+0,00001 \mathrm{a}^{2}-0,00002^{* *} \mathrm{ta}$ - $0,000005^{* *} \mathrm{t}^{2}\left(\mathrm{R}^{2}=0,70\right)$

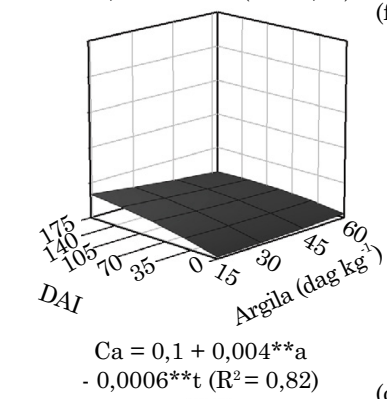

(f)

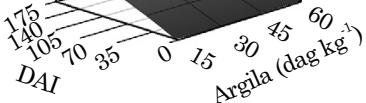

$\mathrm{Mg}=0,04+0,0002^{* *} \mathrm{t}\left(\mathrm{R}^{2}=0,47\right)$

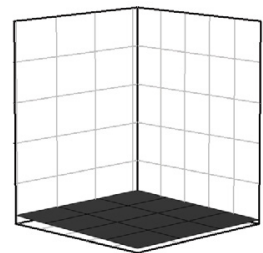

$\mathrm{Mg}=0,03-0,0003 \mathrm{a}+0,0007^{* *} \mathrm{t}$ $+0,00001 a^{2}-0,00001^{* *}$ ta $-0,00000005 t^{2}\left(R^{2}=0,57\right)$

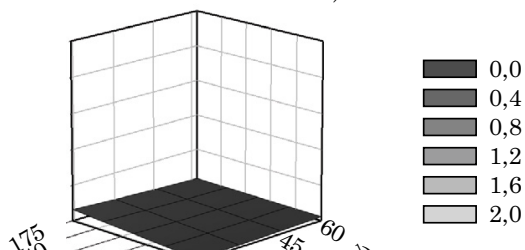

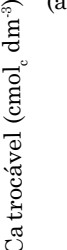
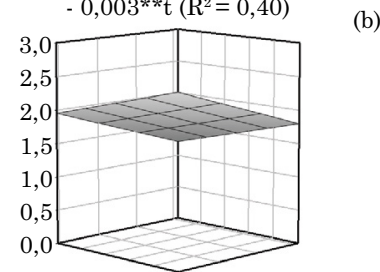

$\mathrm{Ca}=0,12+0,003 * * \mathrm{a}-0,0003 \mathrm{t}$

(d) $\quad-0,000004^{*} \mathrm{t}^{2}\left(\mathrm{R}^{2}=0,85\right)$

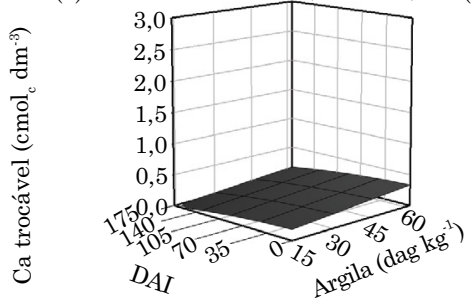

(b)

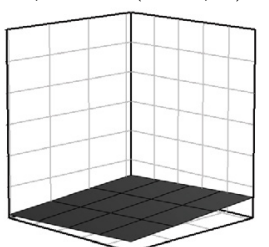

$\mathrm{Ca}=0,13+0,0032 * * \mathrm{a}+0,0004 \mathrm{t}$

(e)

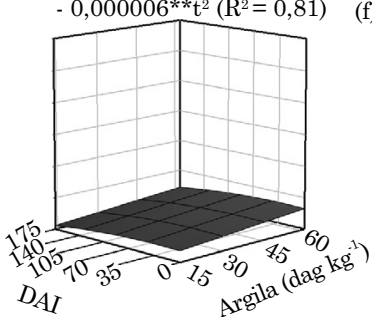

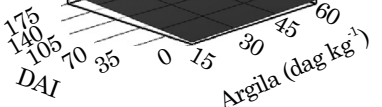

$\mathrm{Ca}=0,13+0,003459^{* *} \mathrm{a}$ - $0,001^{* *} \mathrm{t}\left(\mathrm{R}^{2}=0,82\right)$

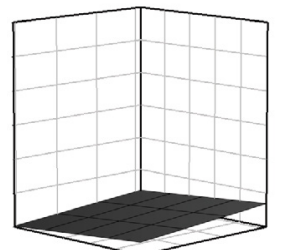

$\mathrm{Ca}=0,15+0,003^{* *} \mathrm{a}$ - $0,001^{* *} \mathrm{t}\left(\mathrm{R}^{2}=0,76\right)$

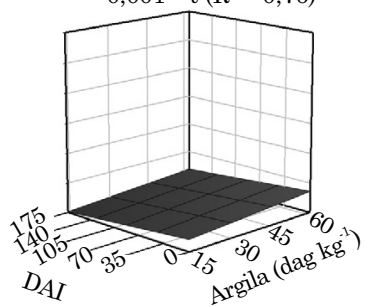

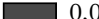

$\square 0,5$

1,0

$\square 1,5$

$\square 2,0$

2,5

$\square 3,0$

Figura 3. Teores de K disponível (Mehlich-1) e Mg e Ca trocáveis (KCl) nos solos com fontes inorgânicas dos nutrientes (a), sem adição de nutrientes e resíduo (b); e com resíduo de: milho (c), braquiária (d), feijão (e) e estilosantes (f). * e**: significativos a 5 e $1 \%$, respectivamente, referentes às variáveis: $a$ - teor de argila, $t$ - tempo e ta - interação entre estes. DAI: dias após o início da incubação. 
fonte inorgânica de $\mathrm{P}$, podem estar relacionadas aos processos biológicos, como a imobilização microbiana, e, ou, químicos, representados pela precipitação do P em solução com formas iônicas, principalmente de $\mathrm{Fe}, \mathrm{Al}$ e Ca, e pela adsorção específica (Broggi et al., 2011). Além disso, o tempo de contato do P com a argila aumenta esse tipo de adsorção (Freitas et al.,
2013). O solo arenoso apresentou os maiores teores de P disponível, em relação ao solo com maior teor de argila, principalmente onde há adição de fontes inorgânicas de P e com resíduos de estilosantes. Esse efeito se deve à capacidade-tampão e ao desgaste do extrator Mehlich-1, que é maior em solos com maior teor de argila.
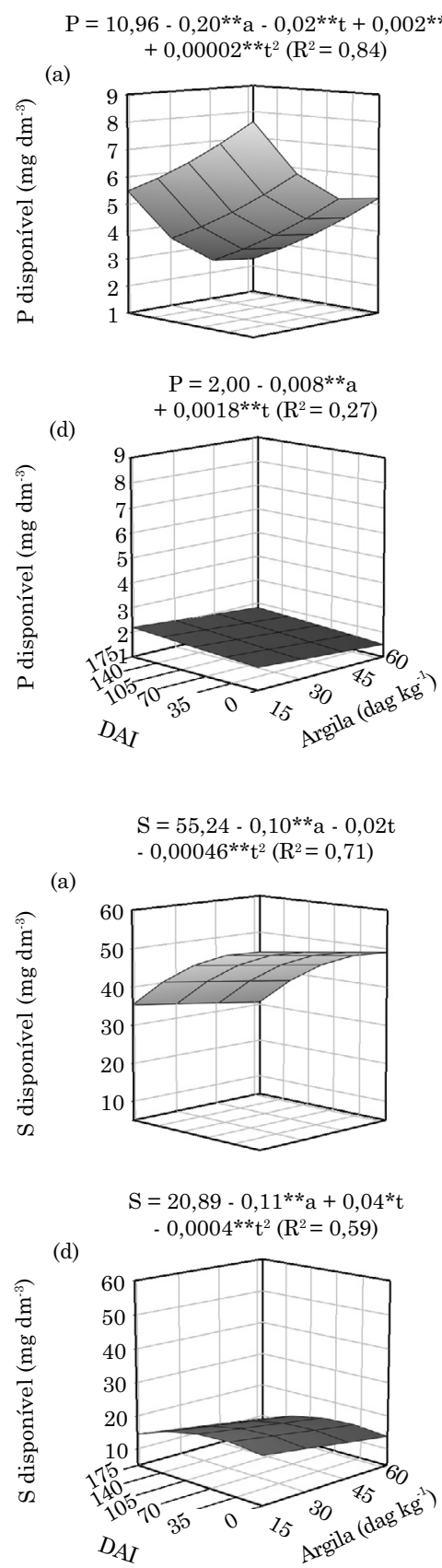

(b) $P=2,07-0,008^{* *} \mathrm{a}$
$-0,003^{* *} \mathrm{t}\left(\mathrm{R}^{2}=0,57\right)$

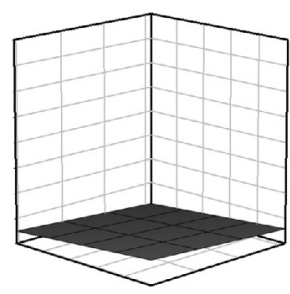

$$
\mathrm{P}=1,92-0,008^{* *} \mathrm{a}+0,007^{* *} \mathrm{t}
$$

(e)

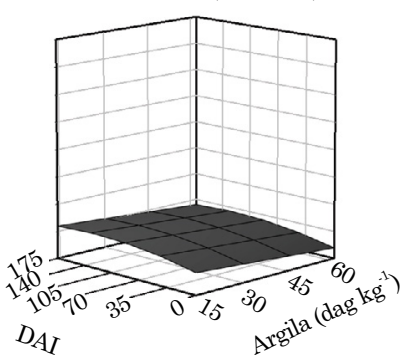

$\mathrm{S}=20,17-0,08 \mathrm{a}+0,008 \mathrm{t}-0,001 \mathrm{a}^{2}$ $+0,0004^{* *}$ ta $-0,0002^{* *} \mathrm{t}^{2}\left(\mathrm{R}^{2}=0,84\right)$

(b)

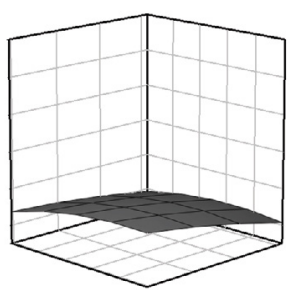

$$
\mathrm{S}=20,74-0,11 \mathrm{a}+0,17^{* *} \mathrm{t}-0,0009 \mathrm{a}^{2}
$$

(e)

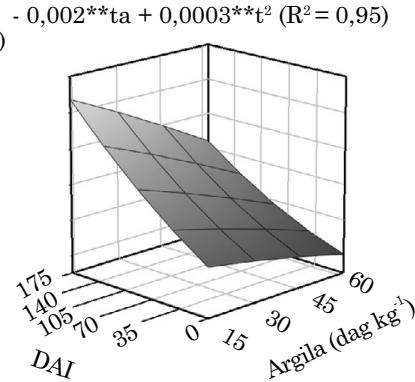

$$
\begin{gathered}
\mathrm{P}=1,79-0,005^{* *} \mathrm{a}+0,005^{* *} \mathrm{t} \\
-0,00004^{* *} \mathrm{t}^{2}\left(\mathrm{R}^{2}=0,31\right)
\end{gathered}
$$

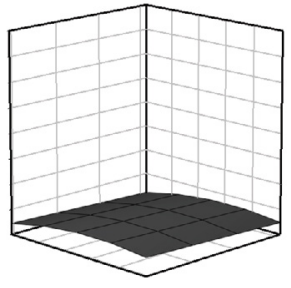

$$
\mathrm{P}=1,60-0,01 \mathrm{a}+0,03^{* * *} \mathrm{t}+0,0001 \mathrm{a}^{2}
$$

(f)

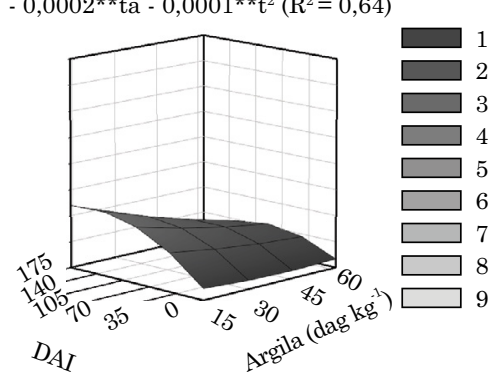

$$
\begin{aligned}
& \mathrm{S}=20,89-0,14^{* *} \mathrm{a}-0,03^{* * *} \mathrm{t}-0,0003 \mathrm{a}^{2} \\
& +0,0008^{* *} \mathrm{ta}-0,0002^{* * *} \mathrm{t}^{2}\left(\mathrm{R}^{2}=0,85\right)
\end{aligned}
$$

(c)
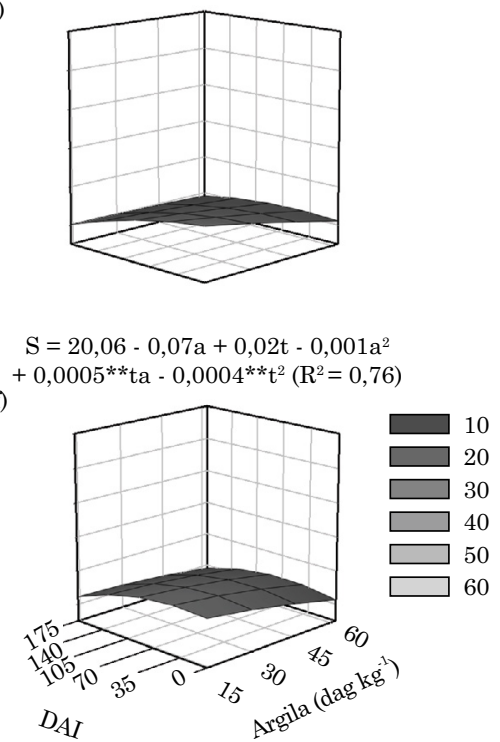

Figura 4. Teores disponíveis de $\mathrm{P}$ (Mehlich-1) e S (Fosfato de cálcio em ácido acético) nos solos com fontes inorgânicas dos nutrientes (a), sem adição de nutrientes e resíduo (b); e com resíduo de: milho (c), braquiária (d), feijão (e) e estilosantes (f). * e **: significativos a 5 e $1 \%$, respectivamente, referentes às variáveis: a - teor de argila, $t$ - tempo e ta - interação entre esses. DAI: dias após o início da incubação. 
Nos solos com resíduos de braquiária, milho e estilosantes, e também no controle com aplicação de fontes inorgânicas de nutrientes, observou-se diminuição, ao longo do tempo, dos teores disponíveis de S (Figura 4). Essa diminuição pode estar relacionada a fatores como a imobilização pela biomassa microbiana e adsorção específica de sulfato, como constatado por Blum et al. (2013). $\mathrm{O}$ aporte de resíduo e as condições do meio de incubação favoreceram a atividade microbiana e assim a exigência desses em nutrientes, promovendo reduções dos teores disponíveis de $\mathrm{S}$ nos solos por imobilização, especialmente com os resíduos de braquiária, milho e estilosantes que possuíam menores teores de S. A manutenção da atividade e o desenvolvimento dos microrganismos seguem requisitos estequiométricos entre o $\mathrm{C}$ e os nutrientes, como N, P e S, principalmente, o que controla os processos de imobilização e mineralização no solo (Manzoni et al., 2010; Mooshammer et al., 2012). Porém, solos com resíduo de feijão tiveram os teores de $\mathrm{S}$ aumentados com a incubação, principalmente em solo arenoso, demonstrando o potencial desse resíduo como fonte de $\mathrm{S}$ em solos agrícolas. Esse efeito é em razão do maior teor de $\mathrm{S}$ nesse resíduo, onde a mineralização sobrepõe a imobilização, não havendo, nesse caso, a necessidade de microrganismos decompositores requerer $\mathrm{S}$ do solo para manutenção de sua atividade.

$\mathrm{O}$ menor teor de $\mathrm{S}$ disponível nos solos com maior teor de argila está relacionado à maior capacidade-tampão e adsorção específica, conforme demonstrado por Blum et al. (2013); também, se relaciona ao desgaste do extrator, em semelhança ao Mehlich-1 para extração de $\mathrm{P}$, onde o fosfato monocálcico em ácido acético tem a capacidade de extrair maiores quantidades de $\mathrm{S}_{-} \mathrm{SO}_{4}{ }^{2-}$ em solos arenosos do que em argilosos, sendo sensível à capacidade-tampão de sulfatos.

\section{Taxa de recuperação dos nutrientes}

A taxa de recuperação pelos extratores indica a quantidade do nutriente extraído por unidade do nutriente aplicado, seja por fontes inorgânicas ou pela mineralização de nutrientes do resíduo cultural. Desse modo, reflete a fração do nutriente adicionado ao solo, que está disponível às plantas.

As taxas de recuperação de $\mathrm{K}$ foram crescentes no tempo, alcançando valores próximos a $80 \%$, para solos com menor teor de argila com resíduos de feijão, estilosantes e milho; e $60 \%$, para os com braquiária (Figura 5). Tais dados corroboram, parcialmente, com os resultados obtidos por Medeiros et al. (2010), os quais, ao aplicarem doses de $\mathrm{K}$ em solos com texturas arenosa, média e argilosa, observaram que as taxas de recuperação variaram entre 80 e $100 \%$, com maiores taxas para solos arenosos, em razão do menor poder-tampão de K, expresso pela CTC.
Baixas taxas de recuperação para $\mathrm{Ca}$ e $\mathrm{Mg}$ foram observadas nos solos com aporte de resíduos culturais, o que indica que a complexação por ânions orgânicos e, ou, a imobilização microbiana ocorrida nos solos podem ser as principais vias para reduzir a disponibilidade desses elementos às plantas, quando comparado às taxas encontradas nos solos com aplicação de fontes inorgânicas. Esse efeito ocorreu principalmente com o Ca, onde foram observadas taxas de recuperação negativas para esse nutriente em solos com resíduo cultural, demonstrando que os teores de $\mathrm{Ca}^{2+}$ no solo do controle absoluto foram maiores do que com resíduos (Figura 5). As taxas de recuperação de $\mathrm{Ca}$ e $\mathrm{Mg}$ observadas nos solos com fontes inorgânicas dos nutrientes corroboram as observadas por Prezotti (2001), em um estudo com aplicação de doses de $\mathrm{Ca}$ e $\mathrm{Mg}$ em cafeeiro, que observaram taxas de recuperação médias de 76 e $80 \%$, respectivamente.

As taxas de recuperação de $\mathrm{P}$ foram diferentes quanto ao tipo de resíduo aportado e baixas quando comparadas aos outros macronutrientes estudados (Figura 6). Pequenas taxas de recuperação também foram encontradas no estudo desenvolvido por Broggi et al. (2010) e Alvarez V. et al. (2014), o que reflete preocupação por causa da grande retenção de $\mathrm{P}$ no solo, principalmente por adsorção específica em solos brasileiros, resultando em baixa aquisição de $\mathrm{P}$ pelas plantas. Cerca de 10 a $30 \%$ do $\mathrm{P}$ aplicado no solo é recuperado ou aproveitado pelas plantas (Syers et al., 2008). As maiores taxas de recuperação de $\mathrm{P}$ são observadas nos solos com resíduos de milho e feijão, especialmente nos solos de texturas média e argilosa (Figura 6). Esse fato pode estar relacionado com a lenta decomposição e mineralização de $\mathrm{P}$ desses resíduos, que favoreceu menor retenção desse nutriente no solo. Menor adsorção e maior aproveitamento de $\mathrm{P}$ pelas plantas foi observado por Urrutia et al. (2013), quando utilizaram fertilizante fosfatado de liberação lenta.

Para o S, as maiores taxas foram obtidas em solos com resíduo de feijão, enquanto as menores taxas foram observadas nos solos com resíduo de milho, principalmente nos com menor teor de argila (Figura 6), o que está relacionado com a imobilização microbiana de S, por causa da baixa quantidade desse nutriente no resíduo de milho. Em outros estudos, observou-se que as taxas de recuperação de S no solo, pelo extrator, são variáveis, com valores próximos a $50 \%$ (Alvarez V. et al., 2014) e $15 \%$ do S aplicado (Prezotti, 2001).

De maneira geral, o estudo demonstrou que sistemas de recomendação de corretivos e fertilizantes, que visam os resíduos culturais como fonte de nutrientes para as plantas, devem considerar e contabilizar a disponibilidade desses nutrientes nos solos. 
$\mathrm{K}=99,32-0,07 \mathrm{a}-0,03 * \mathrm{t}\left(\mathrm{R}^{2}=0,10\right)$

(a)

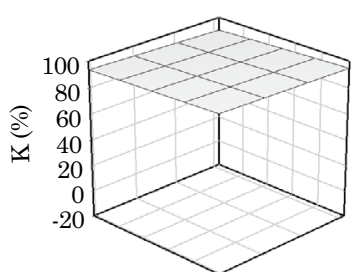

$\mathrm{K}=-0,45+0,55^{* *} \mathrm{t}-0,0006^{* *} \mathrm{t}^{2}\left(\mathrm{R}^{2}=0,97\right)$

(d)

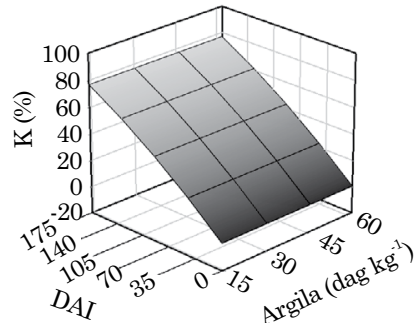

$\mathrm{Mg}=83,55+0,22 \mathrm{a}-0,18^{* *} \mathrm{t}-0,009^{* *} \mathrm{a}^{2}$

(a) $+0,003^{* *} \mathrm{ta}+0,0003 \mathrm{t}^{2}\left(\mathrm{R}^{2}=0,52\right)$

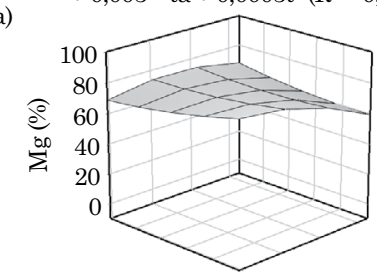

$\mathrm{Mg}=-0,54-0,11 \mathrm{a}+0,39 * * \mathrm{t}+0,002 \mathrm{a}^{2}$

(d)

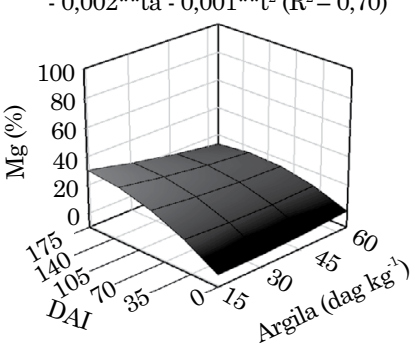

$\mathrm{Ca}=103,19-0,35^{* *} \mathrm{a}-0,08^{* *} \mathrm{t}\left(\mathrm{R}^{2}=0,41\right)$

(a)



$\mathrm{Ca}=3,27-0,09^{* *} \mathrm{a}+0,16^{* * *} \mathrm{t}-0,0009^{* *} \mathrm{t}^{2}\left(\mathrm{R}^{2}=0,38\right)$

(d)

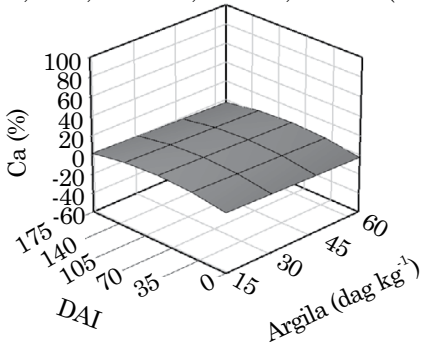

(b)
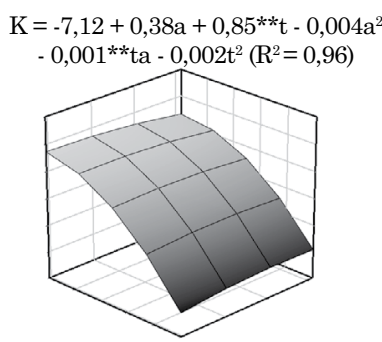

$\mathrm{K}=-7,94+0,54^{* *} \mathrm{a}+0,69^{* *} \mathrm{t}-0,01^{* *} \mathrm{a}^{2}$

(e)

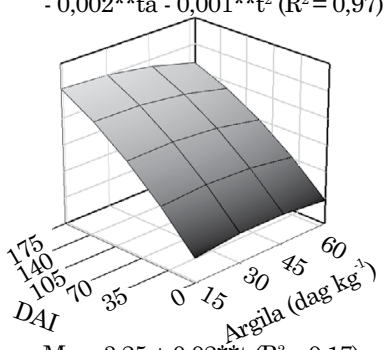

(b)

$\mathrm{Mg}=3,25+0,02^{* * *} \mathrm{t}\left(\mathrm{R}^{2}=0,17\right)$

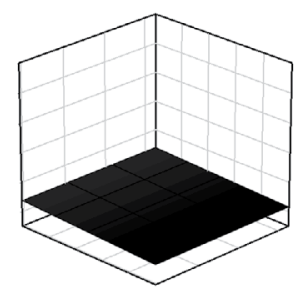

$\mathrm{Mg}=-0,52-0,13 \mathrm{a}+0,17^{* *} \mathrm{t}+0,002 \mathrm{a}^{2}$

(e)

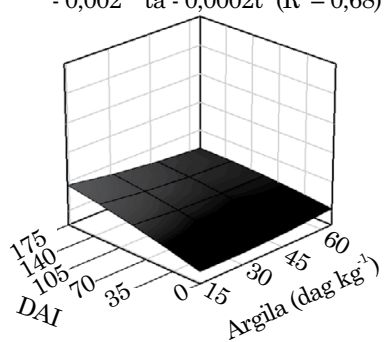

$\mathrm{Ca}=4,07+0,18 \mathrm{t}-0,002^{* *} \mathrm{t}^{2}\left(\mathrm{R}^{2}=0,48\right)$

(b)

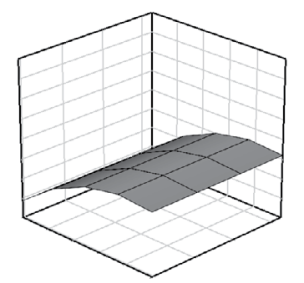

$\mathrm{Ca}=13,60-0,14 \mathrm{a}-0,16^{* *} \mathrm{t}\left(\mathrm{R}^{2}=0,34\right)$

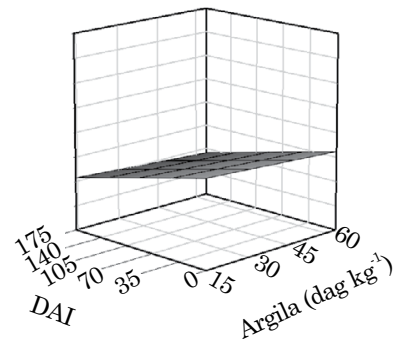

$\mathrm{K}=-1,06+0,20 \mathrm{a}+0,59 * * \mathrm{t}-0,004 \mathrm{a}^{2}$

(c)
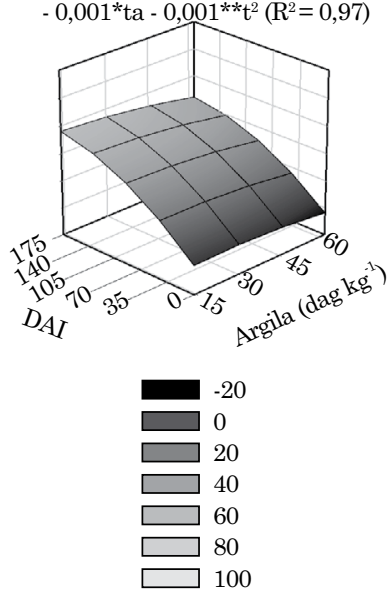

$\mathrm{Mg}=-2,42+0,03 \mathrm{a}+0,30 * * \mathrm{t}+0,0002 \mathrm{a}^{2}$

(c)
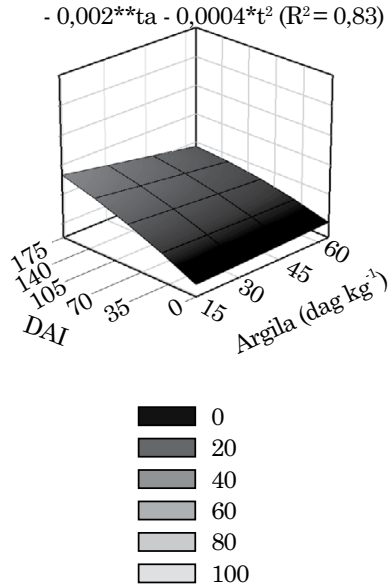

$\mathrm{Ca}=3,10-0,10 * \mathrm{a}+0,188^{* *} \mathrm{t}$

(c)

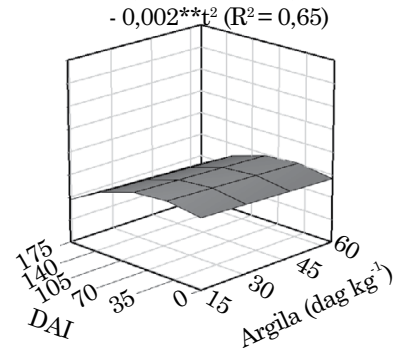

Figura 5. Taxas de recuperação do K, Ca e Mg, pelos extratores, nos solos com fontes inorgânicas dos nutrientes (a); e com resíduo de: milho (b), braquiária (c), feijão (d) e estilosantes (e). * $\mathrm{e}$ **: significativos a 5 e $1 \%$, respectivamente, referentes a: a - teor de argila, $t$ - tempo e ta - interação entre esses. DAI: dias após o início da incubação. 
(a)

$\mathrm{P}=11,88-0,20^{* *} \mathrm{a}-0,03^{* *} \mathrm{t}+0,002^{* *} \mathrm{a}^{2}$
$+0,0001^{* *} \mathrm{t}^{2}\left(\mathrm{R}^{2}=0,63\right)$

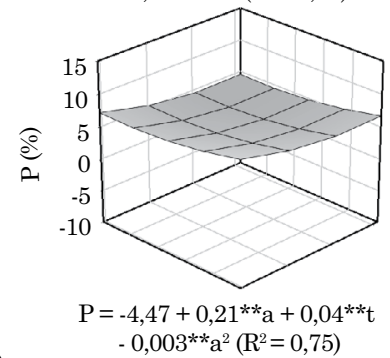

(d)

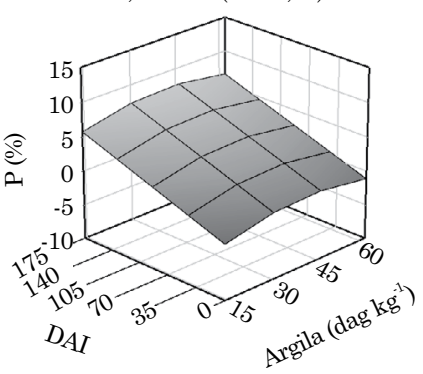

(a)

$$
\mathrm{S}=33,43+0,03 \mathrm{a}+0,06 \mathrm{t}+0,005^{*} \mathrm{a}^{2}
$$$$
\text { - } 0,001^{* *} \text { ta }-0,0004 \mathrm{t}^{2}\left(\mathrm{R}^{2}=0,70\right)
$$

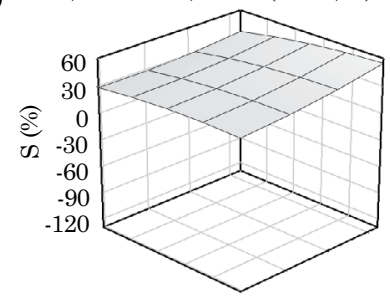

$\mathrm{S}=2,15-0,0024 \mathrm{a}+0,15^{* * *} \mathrm{t}-0,001 \mathrm{a}^{2}$

(d)

$$
-0,001^{*} \mathrm{ta}+0,001^{* *} \mathrm{t}^{2}\left(\mathrm{R}^{2}=0,94\right)
$$

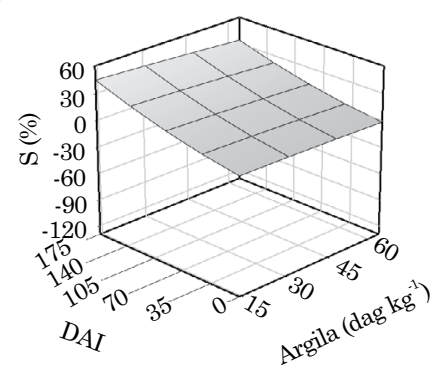

(b)
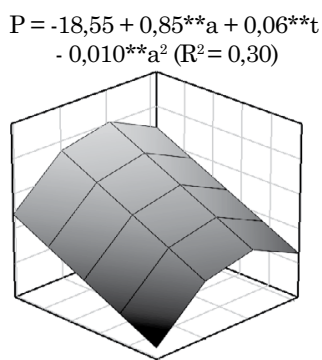

$\mathrm{P}=-2,44+0,05 \mathrm{a}+0,08^{* * *} \mathrm{t}-0,0004 \mathrm{a}^{2}$

(e)

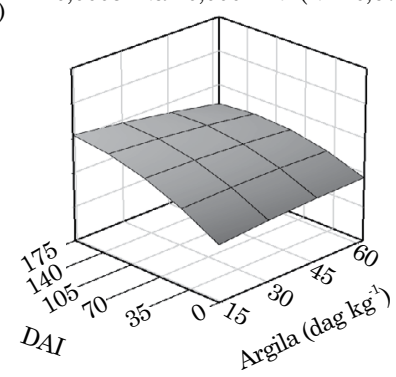

(b)

$$
\begin{gathered}
\mathrm{S}=12,34-1,19 \mathrm{a}-1,14 \mathrm{t}+0,02 \mathrm{a}^{2} \\
+0,01 * * \mathrm{ta}+0,001 \mathrm{t}^{2}\left(\mathrm{R}^{2}=0,75\right)
\end{gathered}
$$

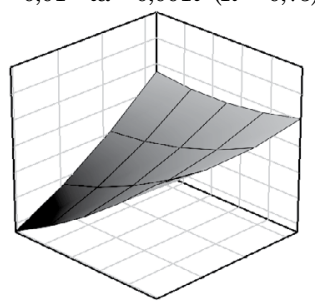

$\mathrm{S}=-2,27+0,09^{* *} \mathrm{a}+0,10^{* *} \mathrm{t}$ $-0,001^{* *} \mathrm{t}^{2}\left(\mathrm{R}^{2}=0,43\right)$

(e)

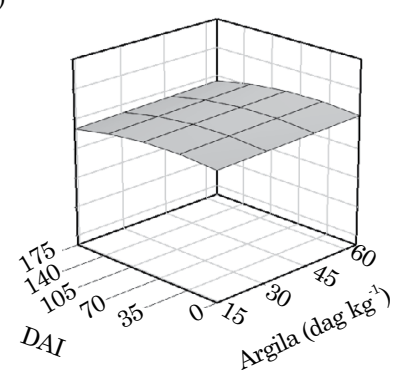

$\mathrm{P}=-0,67+0,03 \mathrm{a}+0,01 \mathrm{t}-0,0004 \mathrm{a}^{2}$ (c) $+0,0003^{* *} \mathrm{ta}+0,00003 \mathrm{t}^{2}\left(\mathrm{R}^{2}=0,70\right)$
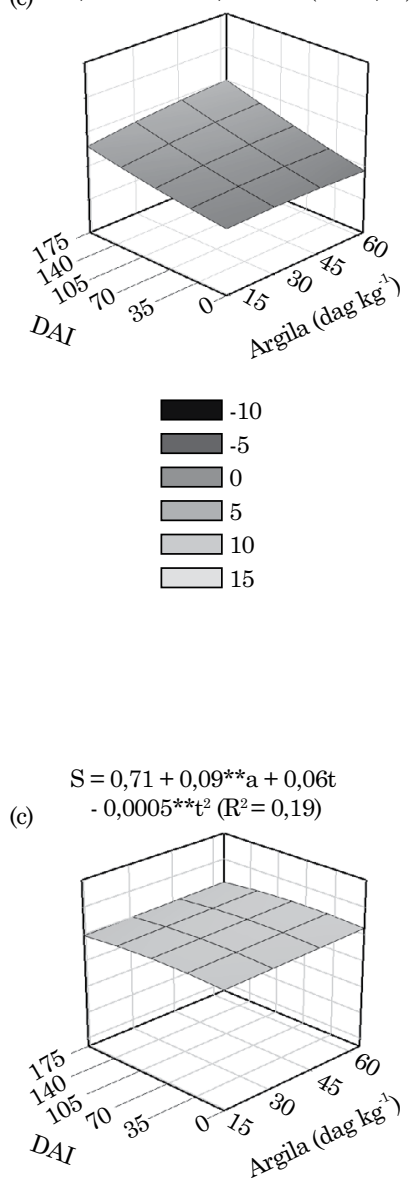

Figura 6. Taxas de recuperação do $\mathrm{P}$ e S, pelos extratores, nos solos com fontes inorgânicas dos nutrientes (a); e com resíduo de: milho (b), braquiária (c), feijão (d) e estilosantes (e). * e **: significativos a 5 e $1 \%$, respectivamente, referentes a: a - teor de argila, $t$ - tempo e ta - interação entre esses. DAI: dias após o início da incubação.

\section{CONCLUSÕES}

Os teores totais de $\mathrm{C}$ orgânico e $\mathrm{N}$, o pH, a disponibilidade do $\mathrm{P}, \mathrm{K}, \mathrm{Ca}, \mathrm{Mg}$ e $\mathrm{S}$ e as respectivas taxas de recuperação no solo são dependentes do tipo de resíduos cultural, principalmente do conteúdo de cada nutriente, do teor de argila e do tempo.

A disponibilidade de $\mathrm{K}$ é a que mais aumenta em solos pelos resíduos culturais e de forma mais pronunciada em solo de textura arenosa; o resíduo de braquiária é potencial fonte de $\mathrm{K}$; e o resíduo de feijão, de S.

As maiores taxas de recuperação de $\mathrm{P}$, pelo extrator Mehlich-1, ocorrem com resíduo de milho nos solos de texturas média e argilosa, em relação aos demais resíduos avaliados.

Independentemente da textura do solo, as quantidade de $\mathrm{P}, \mathrm{K}, \mathrm{Ca}, \mathrm{Mg}$ e $\mathrm{S}$ mineralizadas de resíduos culturais não estão totalmente nas formas disponíveis às plantas. 


\section{AGRADECIMENTOS}

À CAPES, por conceder bolsa de estudos ao primeiro autor. Ao Departamento de Solos/UFV, ao NUTREE e ao Laboratório Isótopos Estáveis, pelo apoio financeiro, espaço físico e instrumental para realização do estudo.

\section{REFERÊNCIAS}

Alvarez V VH, Dias LE, Ribeiro FS, Souza RB, Fonseca CA. Métodos de análises de enxofre em solos e plantas. Viçosa, MG: Universidade Federal de Viçosa; 2001.

Alvarez V VH, Novais RF, Dias LE, Oliveira JA. Determinação e uso do fósforo remanescente. Bol. Inf. SBCS. 2000;25:27-33.

Alvarez V VH, Novais RF, Barros NF, Cantarutti RB, Lopes AS. Interpretação dos resultados das análises de solos. In: Ribeiro AC, Guimarães PTG, Alvarez V VH, editores. Recomendações para o uso de corretivos e fertilizantes em Minas Gerais $-5^{\mathrm{a}}$. Aproximação. Viçosa, MG: Comissão de Fertilidade do Solo do Estado de Minas Gerais; 1999. p.43-60.

Alvarez V VH, Santos AF, Santos GLAA, Matta PM. Fertilização de plantas ornamentais pelo método requerimento-suprimento: proposição de técnica experimental. R Bras Ci Solo. 2014;38:532-43.

Associação Nacional para Difusão de Adubos - ANDA. Principais indicadores do setor de fertilizantes. [Acessado em: 10 jun. 2014]. São Paulo: 2014. Disponível em: http://www.anda.org.br/ estatistica/Principais_Indicadores_2014.pdf.

Blum SC, Caires EF, Alleoni LRF. Lime and phosphogypsum application and sulfate retention in subtropical soils under no-till system. J Soil Sci Plant Nutr. 2013;13:279-300.

Bonfim EMS, Freire FJ, Santos MVF, Silva TJA, Freire MBGS. Níveis críticos de fósforo para Brachiaria brizantha e suas relações com características físicas e químicas em solos de Pernambuco. R Bras Ci Solo. 2004;28:281-8.

Braga JM, Defelipo BV. Determinação espectrofotométrica de fósforo em extratos de solo e material vegetal. $\mathrm{R}$ Ceres. 1974;21:73-85.

Broggi F, Freire FJ, Freire MBGS, Nascimento CWA, Oliveira AC. Avaliação da disponibilidade, adsorção e níveis críticos de fósforo em diferentes solos. R Ceres. 2010;57:247-52.

Broggi F, Oliveira AC, Freire FJ, Freire MBGS, Nascimento CWA. Fator capacidade de fósforo em solos de Pernambuco mineralogicamente diferentes e influência do $\mathrm{pH}$ na capacidade máxima de adsorção. Ci Agrotec. 2011;35:77-83.

Cantarutti RB, Barros NF, Martinez HEP, Novais RF. Avaliação da fertilidade do solo e recomendação de fertilizantes. In: Novais RF, Alvarez V VH, Barros NF, Fontes RLF, Cantarutti RB, Neves JCL, editores. Fertilidade do solo. Viçosa, MG: Sociedade Brasileira de Ciência do Solo; 2007. p.769-872.

Duarte IN, Sousa RTX, Korndorfer GH, Fontoura PR, Soares RAB. Biotita: fonte de potássio para agricultura. Biosci J. 2012;28:98-103.

Empresa Brasileira de Pesquisa Agropecuária - Embrapa. Centro Nacional de Pesquisas de Solos. Manual de métodos de análises de solo. $2^{\text {a }}$.ed. Rio de Janeiro: 2011.
Empresa Brasileira de Pesquisa Agropecuária - Embrapa. Sistema brasileiro de classificação de solos. $2^{\text {a }}$. ed. Rio de Janeiro: 2006.

Farias DR, Oliveira FHT, Santos D, Arruda JA, Hoffmann RB, Novais RF. Fósforo em solos representativos do estado da Paraíba. I - Isotermas de adsorção e medidas do fator capacidade de fósforo. R Bras Ci Solo. 2009;33:623-2.

Franchini JC, Gonzalez-Vila FJ, Cabrera F, Miyazawa M, Pavan MA. Rapid transformations of plant water-soluble organic compounds in relation to cation mobilization in an acid Oxisol. Plant Soil. 2001;63:231-55.

Freitas IF, Novais RF, Villani EMA, Novais SV. Phosphorus extracted by ion exchange resins and Mehlich-1 from Oxisols (Latosols) treated with different phosphorus rates and sources for varied soil-source contact periods. R Bras Ci Solo. 2013;37:667-77.

Manzoni S, Trofymow JA, Jackson RB, Porporato A. Stoichiometric controls on carbon, nitrogen, and phosphorus dynamics in decomposing litter. Ecol Monogr. 2010;80:89-106.

Medeiros JS, Oliveira FHT, Arruda JA, Vieira MS, Fontes MPF. Eficiência de extratores de potássio disponível em solos do estado da Paraíba com graus de desenvolvimento pedogenético diferentes. R Bras Ci Solo. 2010;34:183-94.

Mooshammer M, Wanek W, Schnecker J, Wild B, Leitner S, Hofhansl F, Blöchl A, Hämmerle I, Frank AH, Fuchslueger L, Keiblinger KM, Zechmeister-Boltenstern S, Richter A. Stoichiometric controls of nitrogen and phosphorus cycling in decomposing beech leaf litter. Ecology. 2012;93:770-82.

Moreira FLM, Mota FOB, Clemente CA, Azevedo BM, Bomfim GV. Adsorção de fósforo em solos do estado do Ceará. R Ci Agron. 2006;37:7-12.

Pavinato PS, Rosolem CA. Disponibilidade de nutrientes no solo: Decomposição e liberação de compostos orgânicos de resíduos vegetais. $\mathrm{R}$ Bras Ci Solo. 2008;32:911-20.

Pinto FA, Souza ED, Paulino HB, Curi N, Carneiro MAC. P-sorption and desorption in savanna Brazilian soils as a support for phosphorus fertilizer management. Ci Agrotec. 2013;37:521-30.

Prezotti LC. Sistema para recomendação de corretivos e de fertilizantes para a cultura do café arábica [tese]. Viçosa, MG: Universidade Federal de Viçosa; 2001.

Santos GG, Silveira PM, Marchão RL, Petter FA, Becquer T. Atributos químicos e estabilidade de agregados sob diferentes culturas de cobertura em Latossolo do cerrado. R Bras Eng Agríc Amb. 2012;16:1171-8.

Sinsabaugh RL, Lauber CL, Weintraub MN, AhmedB, Allison SD, Crenshaw C, Contosta AR, Cusack D, Frey S, Gallo ME, Gartner TB, Hobbie SE, Holland K, Keeler BL, Powers JS, Stursova M, Takacs-Vesbach C, Waldrop MP, Wallenstein MD, Zak DR, Zeglin LH. Stoichiometry of soil enzyme activity at global scale. Ecol Lett. 2008;11:1252-64.

Statistics Analyses Systems Institute - SAS. Post-Installation Guide for the SAS $^{\circledR}$ System Version 9 for Microsoft Windows ${ }^{\circledR}$. Cary: 2002.

Syers JK, Johnston AE, Curtin D. Efficiency of soil and fertilizer phosphorus: reconciling changing concepts of soil phosphorus behaviour with agronomic information. Rome: FAO; 2008. (Fertilizer and Plant Nutrition Bulletin, 18).

Tavares MFF, Haberli Júnior C. O mercado de fertilizantes no Brasil e as influências mundiais [Acessado em: 10 jun. 2014]. 
São Paulo: Escola Superior de Propaganda e Marketing; 2011. Disponível em: http://www.espm.br/Publicacoes/CentralDeCases/ Documents/FERTILIZANTES.pdf.

Teixeira MB, Loss A, Pereira MG, Pimentel C. Decomposição e ciclagem de nutrientes dos resíduos de quatro plantas de cobertura do solo. Idesia. 2012;30:55-64.

Urrutia O, Guardado I, Erro J, Mandado M, Garcia-Mina JM. Theoretical chemical, characterization of phosphate-metal-humic complexes and relationships with their effects on both phosphorus soil fixation and phosphorus availability for plants. J Sci Food Agric. 2013;93:293-303.

Viana JHM, Fernandes Filho EI, Schaefer CEGR. Efeito de ciclos de umedecimento e secagem na reorganização da estrutura microgranular de Latossolos. R Bras Ci Solo. 2004;28:11-9.
Wiethölter S. Bases teóricas e experimentais de fatores relacionados com a disponibilidade de potássio do solo às plantas usando o trigo como referência. R Bras Ci Solo. 2007;31:1011-21.

Wisawapipat W, Kheoruenromne I, Suddhiprakarn A, Gilke RJ. Phosphate sorption and desorption by Thai upland soils. Geoderma. 2009;153:408-15.

Yan F, Schubert S, Mengel K. Soil pH increase due to biological decarboxylation of organic anions. Soil Biol Biochem. 1996;28:617-24.

Yeomans JC, Bremner JM. A rapid and precise method for routine determination of organic carbon in soil. Commun Soil Sci Plant Anal. 1988;19:1467-76.

Zhang W, Wang X, Wang S. Addition of external organic carbon native soil organic carbon decomposition: A meta-analysis. PlosOne. 2013;8:1-6. 